\title{
CORREIO TEATRAL: FRAGMENTOS DE UM DISCURSO CRIATIVO
}

\author{
Walter Lima Torres Neto
}

O emprego da troca de cartas entre personagens foi um procedimento dramatúrgico bastante usual no teatro e de grande importância para estrutura dramática de boa parte das peças do repertório ocidental. Duas breves hipóteses sobre a origem dessas missivas, que circulam, inclusive hoje, pelas tramas dos roteiros cinematográficos e televisivos: a primeira hipótese, de cunho histórico associado à convenção do espetáculo, é que as cartas teriam surgido desde quando a dramaturgia se viu fora da influência do teatro antigo - visto que o teatro antigo reservava ao personagem do Mensageiro, do Arauto, ou do Adivinho o privilegiado lugar de enunciador do antecedente da ação ou do futuro destino, desditoso e trágico do herói. A segunda hipótese acerca do aparecimento dessas cartas sobre o palco poderia ser de matriz sociológica, isto é, essa aparição estaria condicionada ao momento em que o personagem, ao ser composto como reflexo do Real, teria se alfabetizado e aprendido a escrever e, sobretudo, a ler.

É certo que a troca de cartas ganhou um lugar de destaque, especialmente nas comédias. Entre enamorados, as cartas são levadas e trazidas por Aias, Pajens, Empregados e fiéis servidores, adjuvantes devotados. Na luta entre o ardor juvenil e o rigor da oposição paterna, familiar, muitas vezes essas missivas são interceptadas. Os pais zelosos, e encolerizados, acabam por se deixar enredar, enganar e embrulhar pelo embuste desses estratagemas que fazem avançar a ação dramática, dando lugar a situações tanto de comicidade quanto de dramaticidade.

No teatro, marcadamente, burguês, desde a matriz do drama sério idealizado por Diderot no séc. XVIII, as cartas trabalham no interior da estrutura ficcional de forma circular, isto é, abrindo ou fechando um ciclo expresso na cena, no quadro ou no ato. Circulam entre o dentro e o fora do local da ação, atravessam o tempo e precipitam a ação dramática para o seu desfecho. As cartas são o lugar do segredo privado que quando se torna público é para acrescentar mais um degrau à narrativa cênica. Levam e trazem as disposições para o amor, bem como as intrigas, traições, anúncios de mortes, 
resgates, declarações, numa palavra, premonições e fatos consumados. As cartas do ponto de vista dramático são, em suma, anúncios, avisos que indiciam o desfecho da ação, quando não são, elas próprias, o objeto deste mesmo desfecho.

Porém, dentro da cultura e prática teatral, como se pode deduzir, há cartas estabelecidas graças ao rigor de um plano de uma obra ficcional e outras cartas trocadas entre os agentes criativos da cena teatral, no calor da concepção da experiência criativa. E é dessa correspondência que vamos nos ocupar a seguir.

\section{A distância encurtada pela palavra}

O teatro é uma prática social coletiva, cujo processo criativo é coletivizado. E, dentro da cultura e prática teatral ocidental, a dinâmica do processo criativo em vista à realização cênica nem sempre foi a mesma. Ao longo do século XVI, tanto no teatro elisabetano quanto no teatro clássico francês, os autores escreviam as "partes" dos referentes papéis (comportando suas réplicas e as respectivas deixas) e as entregavam aos atores encarregados dos personagens. Esse expediente era adotado para minimizar o plágio e a preocupação com editores oportunistas, inescrupulosos. Além do que, a autoria da obra e a coordenação da transposição do texto à cena eram, na maioria das vezes, tarefas acumuladas pelos próprios autores dramáticos. Esta prática da distribuição das "partes" atravessa o século XVIII, ao menos na França, apesar dos alertas de Diderot quando escreve seu Discurso sobre a poesia dramática, já chamando atenção dos agentes criativos sobre a necessidade de conhecimento da totalidade do poema dramático. Entretanto, ainda na segunda metade do século XIX, este procedimento de distribuição das "partes" é verificado, e inclusive no Brasil observa-se que se alonga até os primeiros anos do século XX.

Somente na virada do século XIX para o XX, com a instituição do moderno diretor teatral, associada aos diretores Stanislavski na Rússia e André Antoine na França, é que houve uma sistematização acerca do estudo da peça teatral, do poema dramático como um todo, interrompendo esse hábito quanto ao jogo das partes. Desde então, o texto teatral, como um grande organismo vivo, passou a ser submetido a uma "dissecação científica". Trata-se de uma leitura analítica e interpretativa acerca das intenções do autor, do poeta, na presença do conjunto dos agentes criativos (atores, cenógrafos, músicos, figurinistas, iluminadores, etc). E é nesse instante que os textos deixaram de dizer somente o que o autor acreditava dizer, para dizer também algo que ele não estimava considerar. Deve a leitura da peça feita pelo coletivo teatral, em voz 
alta, orientada pelo diretor teatral, descobrir os objetivos mais recônditos da obra, suas intenções. Esse trabalho de secionar a obra e traduzir suas intenções, algumas vezes, era realizado pelo próprio autor, que, convidado pela trupe, fazia a leitura de sua peça ao elenco no intuito de apresentá-la. Dessa forma, como conseqüência direta desse novo procedimento de entendimento do texto teatral, que poderíamos considerar como moderno, temos uma espécie de embate intelectual entre os agentes criativos, na busca pela definição de um sentido e de um significado para a encenação de um texto teatral.

Porém, em nossa cultura e prática teatral, verifica-se que a distância física entre os agentes criativos da cena, antes de ter sido vencida pela internet, foi atenuada por séries de trocas de cartas. Essa troca de correspondência entre agentes criativos não se limita, exclusivamente, ao processo criativo, agregando outras situações. E é sobre essas variadas situações de correspondência de teor teatral, envolvendo problemas estéticos, ou de relacionamento, aconselhamentos, etc que vamos tratar, ao selecionar alguns fragmentos epistolares que caracterizam a troca de cartas entre: autor e diretor; autor e editor; diretor e cenógrafo; diretor e ator; crítico e atriz, o que configuraria uma breve visão de um "correio teatral".

\section{Comentando sua obra: de Tchéckov para Suvórin}

Parte de um volumoso e abrangente conjunto de cartas escritas por Anton Pávlovitch Tchékhov (1860-1904), que remonta a 4.440 missivas publicadas na Rússia, endereçadas a diferentes correspondentes, foi o objeto de importante trabalho de Sophia Angelides ${ }^{1}$. A totalidade dessa correspondência trocada entre Tchékhov e os mais diversos colaboradores, editores, familiares, amigos encerra um período que vai de 1875 até 1904. E nesse conjunto destacam-se os mais diversos assuntos afeitos ao universo literário, teatral, social, familiar, existencial do autor russo (ANGELIDES, 1995: 15). O que chama atenção nesse conjunto epistolar, e que foi, inteligentemente, enfatizado na seleção e nos comentários de Angelides em seu trabalho, é exatamente a possibilidade do leitor se iniciar à poética tchecoviana graças ao conteúdo das cartas.

Por exemplo. Em carta de dezembro de 1888, a Alekséi Suvórin, editor do jornal Novo Tempo de São Petersburgo, e importante interlocutor de Tchékhov, observa-se

\footnotetext{
${ }^{1}$ ANGELIDES, Sophia. A. P. Tchékhov: cartas para uma poética. São Paulo. EDUSP, 1995. A pesquisa de Sophia Angelides se desdobra ainda na apresentação e analise de outros conjuntos epistolares. Carta e literatura: a correspondência entre Tchékhov e Gorki. São Paulo. EDUSP, 2002. Do mesmo Tchevov pode-se ler na tradução de Aurora Fornoni Bernardini e Homero Freitas de Andrade suas Cartas a Suvórin (1886-1891). São Paulo. EDUSP, 2001.
} 
como o autor do Jardim das cerejeiras detalha o caráter, o perfil psicológico do personagem título de sua primeira peça teatral, Ivanov. A peça estreara um ano antes no Teatro Korch, de Moscou, e posteriormente teve remontagem no Teatro Aleksandrinski, em São Petersburgo, em 1889. Em ambas as ocasiões, não foi muito bem recebida pelo público e, sobretudo pouco entendida pelos agentes criativos envolvidos nas montagens $^{2}$ :

Eu concebo as minhas personagens da seguinte forma: Ivanov é nobre, de formação universitária, sem nada de notável; um temperamento que se inflama com facilidade, ardente, propenso às paixões, franco e honesto, como a maioria dos nobres instruídos. Ele viveu em sua propriedade e serviu no zemstvo. (...) O passado dele é maravilhoso, como a maioria dos intelectuais russos. Não há, ou quase não há, nenhum russo da nobreza ou de formação universitária que não se vanglorie de seu passado. Presente é sempre pior do que o passado. (...)" (In ANGELIDES, 1985: 123-124).

Essa breve exposição, espécie de gênese sobre o personagem ficcional pelo seu autor, dá uma idéia acerca do problema do entendimento de uma nova dramaturgia realista e poética, eivada de subtextos e de conteúdos "não ditos" que deveriam ser completados pelo jogo dos atores, com uma atuação que fugisse da convenção dos personagens tipos, na qual a grande maioria dos atores estava cristalizada na época. Trata-se do momento em que Tchékhov pesquisa uma nova concepção para o personagem de teatro, tornandoo mais complexo em sua relação consigo mesmo e com os demais personagens de uma composição dramática. O teor da exposição do autor russo vai no sentido de fazer ver, neste caso a Suvórin, essa variedade de caráter que se situa entre o particular do personagem e o comportamento geral da cultura russa. É notável o trabalho de Tchékhov sobre o real, e sem necessariamente ser realista ou naturalista como fora entendido, sobretudo por Stanislavski. Trata-se, ao fim e ao cabo, de um exemplo de uma outra mentalidade, uma nova visão acerca da percepção do ser ficcional e sua tradução sobre o palco. Contudo, para essa nova concepção de personagem, seria necessária a intervenção de um moderno diretor teatral que compreendesse a complexidade desses novos caracteres e propusesse uma nova prática para os atores poderem atuá-los. Isso viria com Stanislvavki e as pesquisas subseqüentes no Teatro de Arte de Moscou.

\footnotetext{
${ }^{2}$ Sobre as considerações de Tchékhov sobre esse fracasso pode-se ler sua carta escrita ao seu irmão. Cf. (ANGELIDES: 1985, 77-79)
} 


\section{Afinando o discurso criativo: de Tchékhov para Stanislavski}

Numa abrangente pesquisa sobre a correspondência trocada entre os diversos agentes criativos do Teatro de Arte do Moscou, que remonta inicialmente a uma seleção de 1.117 cartas, Cristiane Layher Takeda selecionou 431 missivas, das quais, posteriormente escolheu 283, que segundo ela caracterizam intensamente a vida teatral desse conjunto artístico que continua sendo um divisor de águas na cultura e prática teatral no ocidente ${ }^{3}$. Esse conjunto de correspondências retrata, em suma, uma complexa teia de relacionamentos interpessoais, que por sua vez nos ensinam sobre as condições humanas e materiais para a produção das encenações e as condições atinentes aos processos criativos que relacionam quase sempre autores, diretores e atores. É verdade que estamos num período textocêntrico, onde as discussões tomam por base o texto teatral, e nesse caso, por um lado, temos o autor defendendo os princípios e idéias que ele entende como atinentes a sua obra, espécie de essência ou manancial que seria a depositária de uma verdade para criação cênica; e por outro, temos o coletivo de atores, capitaneado pelo diretor, que interpreta a peça a sua maneira, e forja uma aparência nem sempre exata segundo o princípio idealizado pelo autor. Portanto, adequar os atores ao princípio fundamental da peça com o intuito de que suas atuações possam servir à obra e não o contrário, este foi o esforço de Stanislávski.

Entretanto, em carta de janeiro de 1901, Tchékhov chama atenção de Stanislávski acerca de uma passagem da encenação de As três irmãs: "O senhor me conta que, no terceiro ato, quando Natacha anda pela casa durante a noite, ela apaga as velas e procura por bandidos atrás dos móveis. Mas parece-me que seria preferível que ela andasse cruzando o palco em uma linha reta, sem olhar para nada ou ninguém, à Lady Macbeth, com uma vela - desse modo a cena ficaria mais curta e apavorante" (In TAKEDA, 2003: 161). O exemplo é curto, mas significativo. No intuito de dar maior expressão lógica de verdade às ações físicas da atriz, a proposta de Stanislávski é claramente objetiva, explícita até. E, diga-se de passagem, não foram poucas as vezes em que Stanislávski demonstrou um excesso de preocupação "realista", do tipo causa e efeito, sobretudo em relação aos textos de Tchékhov, que transitam entre o dramático e o épico; uma estética simbolista e naturalista; objetividade e subjetividade. A sugestão de Tchékhov aqui é o que poderíamos apontar como uma sugestão claramente poética, uma orientação de cunho cênico à maneira do que seria um texto didascálico. Em parte,

\footnotetext{
${ }^{3}$ TAKEDA, Cristiane Layher. O cotidiano de uma lenda: cartas do Teatro de Arte de Moscou. São Paulo. Editora Perspectiva / FAPESP, 2003.
} 
pode-se deduzir que o melhor conhecimento de um papel ou do todo da obra dramática, visando a sua transposição cênica, no tocante, sobretudo ao conjunto dos textos de Tchékhov com suas nuanças e novas convenções, forjando um "teatro de atmosfera", advenha, exatamente, desse fluxo e refluxo entre as intenções do autor e o entendimento acerca da atribuição de sentido pelo diretor, como o fragmento acima nos permite verificar.

\section{A carta convite: de Jouvet para Procópio}

A circulação de companhias dramáticas ou musicais estrangeiras, sobretudo francesas e italianas (visto que as companhias portuguesas não são consideradas aqui) pelas principais capitais brasileiras sempre foi uma constante entre nós. Em certos momentos, com maior assiduidade, noutros com menor periodicidade, mas sempre de maneira marcante, destacada pela imprensa local, e forjando inclusive um período específico no calendário cultural nacional, onde tinham lugar as tão esperadas "temporadas estrangeiras". Verifica-se uma regularidade nessa circulação até os anos 1950. Deste período em diante, a circulação, na forma de turnês vai deixando de ser tão sistemática.

E não foi diferente, durante os anos de 1941 e 1942 em plena II Guerra Mundial, quando a Companhia do Théâtre Louis Jouvet de Paris ficou retida no Brasil. Ela viera para realizar a temporada de 1941. E devido às proporções que a guerra alcançara a companhia preferiu ficar na América do Sul. Graças a uma colaboração entre as prefeituras de Rio de Janeiro e São Paulo, aliada à determinação de não regressarem à Europa, essa companhia acabou por ficar no Brasil para uma segunda temporada em 1942. E dessa iniciativa Louis Jouvet idealizou então um grande circuito, uma grande turnê, que visitaria as principais capitais e cidades da América do Sul e do Norte, enquanto durasse o conflito internacional ${ }^{4}$.

O que interessa ressaltar pontualmente aqui é que no ano de 1942, Louis Jouvet assistiu, primeiro sozinho, e depois acompanhado dos integrantes de sua companhia ao ator Procópio Ferreira na peça Le medecin malgré-lui de Molière. Sobre a atuação do ator brasileiro em especial Jouvet sinaliza na carta ${ }^{5}$ :

\footnotetext{
${ }^{4}$ JOUVET, Louis. Prestiges e perspectives du théâtre français: quatre ans de tournées em Amérique Latine 1941-1945. Paris. Gallimard, 1945.

${ }^{5}$ A célebre carta foi publicada na sua versão em francês na Revista de Teatro. Rio de Janeiro. SBAT (Sociedade Brasileira dos Autores Teatrais), julho/agosto, 1979. Aqui a tradução dos dois fragmentos é nossa.
} 
Você atuou na peça de Molière partindo de um personagem central que não sai nunca da situação dramática e eu tenho a impressão de que você reencontrou o sentido de uma obra que é para nós perdido por conta de um excesso de refinamentos e de "interpretações".

Tendo apreciado a montagem e, sobretudo, a adaptação/tradução de Procópio Ferreira para esse texto do teatro clássico, Louis Jouvet, idealizando uma futura montagem de Dom Juan de Molière, quando de seu retorno à França, anteviu a possibilidade de aproveitar o ator brasileiro ao seu lado. Dessa forma, Jouvet convida na mesma carta ao célebre ator brasileiro para interpretar o papel de Sganarelle ao seu lado.

Eu desejaria que os atores franceses pudessem vê-lo atuando. Eu desejaria, meu caro amigo, que você pudesse vir um dia à França, interpretar o Medecin malgré-lui, e eu sonho desde que o vi representando Molière, que você aceitasse atuar no papel de Sganarelle na minha montagem para o Dom Juan. Esta é uma das peças de Molière que há muito tempo eu sonho em montar. Eu não vejo hoje em dia outro ator que possa interpretá-la melhor do que você. Você é um grande ator, é preciso que lhe diga, e que todos saibam também.

Procópio Ferreira já era um ator consagrado no Brasil, tanto em relação ao público quanto em relação aos seus pares na década de 1940. Entretanto, a carta escrita por Louis Jouvet, que fora publicada a pedido do próprio Procópio em diversos jornais cariocas na época, colaborou bastante para promover ainda mais o prestígio e a condição de Procópio Ferreira como grande ator brasileiro durante as décadas de 1940 e 1950. Procópio Ferreira se referia a essa carta como a uma condecoração. De certo, a posição de destaque desempenhada por Louis Jouvet na cultura e prática teatral francesa, que nesta altura era ainda de grande influência entre nós, fez com que a carta escrita pelo ator francês soasse naquele momento, e, mesmo ao longo do tempo, como uma prova de distinção das mais fortes a favor de Procópio Ferreira. Note-se que se tratava de uma carta particular, de uma correspondência privada, que, entretanto, ganha os meios de comunicação para dar conhecimento público de algo até então prosaico. A carta se tornou mais do que um vestígio acerca da passagem de companhia francesa pelo Brasil. Procópio torna a carta um documento, uma espécie de certificado de qualidade, de reconhecimento internacional para sua carreira. Procópio Ferreira já havia se apresentado em Portugal, circulado por todo Brasil, e se firmara como o grande ator nacional. Entretanto, Procópio sempre fora considerado, pelos grupos amadores emergentes de caráter modernista, pela intelectualidade e pela crítica moderna da época, que começava a esboçar a renovação teatral, um ator que representava o "velho teatro", 
que se opunha, portanto à modernização da cena, dos processos criativos e produtivos. Nesse caso, as palavras de Louis Jouvet, um discípulo direto de Jacques Copeau, soaram como uma consagração especializada. Louis Jouvet, por seu lado, ficou de fato tão bem impressionado com a atuação do ator brasileiro, que tempos mais tarde, ainda prisioneiro da boa impressão que tivera da atuação de Procópio Ferreira, quando foi encenar, efetivamente, o Dom Juan de Molière em 1948, convidou o ator Fernand René, cujo physique $d u$ rôle, conforme se pode notar à vista das fotografias da montagem, lembrava em tudo o ator brasileiro, que não aceitara o convite para viajar até Paris.

\section{Formando e modelando gerações: de Décio para Cacilda}

Durante os primeiros anos da década de 1940, se estabeleceu uma troca de cartas entre Mário de Andrade e um jovem autor, ansioso por conhecer as opiniões do mestre do modernismo sobre sua primeira obra, Fernando Sabino. A correspondência entre os dois pode ser percebida desde a leitura de Cartas a um jovem escritor, que colige as missivas trocadas entre 1942 e 1945 . São cerca de trinta cartas nesse período de três anos, dirigidas ao autor mineiro, que se iniciava na carreira literária e na vida tributária. Sabe-se que a correspondência de Mário de Andrade, de maneira geral, foi intensa e profícua, tendo diversos interlocutores. Hoje, esse correio artístico literário se constitui em importante fonte para conhecermos os bastidores do modernismo literário e artístico, uma cultura que se impunha devido ao pensamento do próprio Mário de Andrade que provocava uma ressignificação da atitude criativa dos escritores em relação ao Brasil, à arte e à cultura de uma nação. Dessa forma desenhava-se um programa artístico de toda uma geração.

Guardando esse mesmo sentido geracional, seguindo a mesma linha formativa e modelar, no intuito de orientar e encorajar, formar e informar, não menos intenso no teor, porém, é o caso de Décio de Almeida Prado. A sua "Carta a uma jovem atriz", única e possivelmente sem resposta, foi publicada no jornal, tendo como destinatário ou leitora ideal a iniciante atriz Cacilda Becker, que, no transcorrer de sua trajetória artística futura, se tornaria símbolo de toda uma geração de atores brasileiros modernos. Ao contrário do exemplo de Mário de Andrade com seu conjunto epistolar, em 1949, Décio de Almeida Prado, que já era um crítico desfrutando de certa notoriedade intelectual na imprensa paulista, inserido na nossa cultura e prática teatral como um espectador privilegiado cujas opiniões trabalhavam na direção da modernização do nosso teatro, também manifestou sua orientação de forma epistolar . 
O período em questão é o do atrito entre o "novo", atrelado às novidades advindas dos grupos amadores e do TBC, e o "velho teatro", identificado por figuras como Procópio Ferreira e Jaime Costa. Trata-se, em particular, do período de renovação da cena teatral paulistana, irradiando sua influência aos demais pontos do país, dentro de um projeto de fortes contornos modernistas, apesar de inspiração francamente eurocêntrica nesse momento. Observam-se grandes modificações quanto ao regime empresarial; ao repertório, à cena, e sobretudo no que concerne o trabalho do ator. Era aí, e Décio de Almeida Prado estava correto, onde se encontrava uma trincheira importante: trabalhar por um novo comportamento criativo baseado numa ética e moral específica, sob um olhar moderno, para o ofício do intérprete, desde sempre um profissional da exibição com forte inclinação a se deixar levar pelo sucesso circunstancial. "O jovem ator já não entra mais no palco como outrora, só e desamparado. Há mestres para orientá-lo, há um público entusiasta para estimulá-lo, e até algumas escolas dramáticas, realmente dignas desse nome, começam a despontar." (PRADO, 1997: 78). Naturalmente, o fundador da Revista Clima alude à fundação do Teatro Brasileiro de Comédias pelo empresário Franco Zampari, que contratara os diretores italianos para encenação de suas produções, ao mesmo tempo em que assinala a criação da Escola de Arte Dramática por Alfredo Mesquita. Orientando a jovem atriz em seu inicio de carreira, o crítico preconizava sobre o seu futuro, afirmando que este (...) "dependerá somente de você mesma, do seu esforço. E, num certo sentido, ninguém poderá ajudá-la, pois a técnica artística não se recebe feita das mãos dos outros: é o resultado de um penoso trabalho individual, apenas facilitado, tornado viável, pelo estímulo exterior a que me referia.” (PRADO, 1997: 78). E após expor longamente sobre os malefícios do artista em ceder às aparências de uma publicidade volátil, concluía sua preleção com uma citação atribuída a Sileno: "A vida fútil nutre-se da aparência. Quer somente parecer; parecer interessante, inteligente, bela, instruída; às vezes quer parecer até boa, altruísta, corajosa. Para as pessoas fúteis, ser não é importante; o importante é parecer." (PRADO, 1997: 80). Não bastaria ser unicamente uma atriz talentosa e promissora ,se não houvesse uma reta condução ética de sua carreira, estimava Décio de Almeida Prado. Só assim o artista da cena conseguiria estabelecer uma carreira sedimentada com uma expectativa de longo prazo. 


\section{A obstinação pelo rigor: de Genet para Roger Blin}

Ao longo do processo de ensaios, quando da estréia da sua peça pela Companhia Renaud-Barrault em 1966, a obstinação pelo rigor na clareza de suas intenções como autor, levou Jean Genet a escrever e enviar uma série de notas e cartas endereçadas a Roger Blin, o diretor de Os biombos. Esse conjunto de notas e cartas acabou por constituir um importante discurso paratextual dos mais significativos, não só para compreensão do conteúdo em si, mas também do que quer dizer seu autor com sua peça e como fazê-lo. Observa-se nessas cartas uma preocupação permanente, ou seria uma insegurança do autor em função de como sua peça poderia ser interpretada. Ao longo da leitura dessas notas e cartas, haveria uma intenção do autor em traduzir suas intenções. É notória sua preocupação em destrinchar, em desdobrar os problemas que advenham tanto da forma quanto do conteúdo exposto na peça. A peça está organizada em dezesseis quadros, e as informações legadas por Genet cobrem os diversos campos do processo criativo. Genet se dedica a esmiuçar questões ligadas aos figurinos dos personagens, detalhando sobre o significado de cores, cortes e texturas mais adequadas aos papéis; ele procura especificar o cenário, além de se preocupar com a sua manipulação, visto que os biombos que dão nome à própria peça, no plano da realidade teatral, devem ser movimentados pelos próprios atores. A iluminação, a sonoplastia, os objetos de cena, o jogo de cena, o ritmo e a fusão de um quadro noutro quadro, são objeto de minuciosa explicitação por parte do autor. Curiosamente, a peça escrita em 1958, quando foi editada em 1961, já comportava um denso texto didascálico que de alguma maneira direcionava bastante a leitura do texto. Porém, quando da montagem da estréia de 1966, as cartas ao diretor surgem como uma argumentação extra-texto a subsidiar o processo criativo, dirigindo-o para o sentido político existencial que ele Genet pretende abordar com seu texto. A título de exemplo, selecionamos esse pequeno fragmento que demonstra a preocupação com o rigor em relação ao trabalho de enunciação do texto pelos atores:

Ao texto de Os biombos deveria ser anexada qualquer coisa que se assemelhasse a uma partitura. É possível. O diretor, tendo em vista os diferentes timbres de voz, inventará um modo de declamação partindo do murmúrio até chegar aos gritos. Frases, torrentes de frases devem ser urradas, outras serão arrulhadas, outras ainda serão ditas dentro do tom habitual de uma conversa. (GENET, 1966: 28-29).

Apesar de termos trazido aqui um brevíssimo instante dessa reflexão de Genet, o que parece estar em jogo, dada a sua preocupação e por isso mesmo o estabelecimento 
desse discurso paratextual com o diretor Roger Blin como destinatário, é a tentativa de assegurar a coerência de uma narrativa. Isto é, Genet como ficcionista, como contador de histórias, estava preocupado com a narratividade, dado inclusive o alto grau de complexidade da estrutura de sua fábula, estabelecida entre dois planos, o dos vivos e dos mortos. E aqui Genet percebe muito bem que a narratividade estaria inscrita na qualidade daquilo que é efetivamente teatral. Isto é, na teatralidade sugerida pela linguagem da encenação. Daí advém sua obsessão em não perder de vista sua mão autoral diante do conteúdo, que por força de uma "leitura" de terceiros poderia dissolver suas preocupações estéticas e políticas. Assegurar a sua condição de autor responsável pelo conteúdo que vai expresso sobre o palco é tornar-se senhor da forma que o expressa, daquilo que a cena e não mais o texto é capaz de narrar. Assegurar essa instância narrativa foi o desejo de Genet com esse conjunto paratextual, que inclusive foi editado em 1966, acompanhado de fotografias dessa primeira encenação.

Como se pode aferir à leitura desses cinco brevíssimos fragmentos, exemplos de paratextos que constituem um correio teatral, cada qual a sua maneira sinaliza a existência de uma fonte a ser explorada por futuras pesquisas, como já nos demonstram os excelentes trabalhos de Sophia Angelides e Cristiane Takeda. Em nosso caso, nos interessou sinalizar o conteúdo de uma mentalidade que expressa a atitude criativa dos agenciadores da cena teatral. Trata-se de analisar a expressão de uma mentalidade particular que subsidia o fazer e o pensar teatral que aflora de um condicionamento social. Efetivamente, trata-se de lançar as bases de análise para a compreensão do processo criativo como uma prática social da própria cultura. Com isso é importante que se conclua observando que não existe, sobretudo no tocante aos exemplos extraídos do teatro brasileiro, uma expressão de juízo afirmando a superioridade do dito "novo teatro", encarnado aqui na figura de Décio de Almeida Prado em sua orientação à atriz Cacilda Becker, por oposição ao "velho teatro", defendido por um ator da estirpe de um Procópio Ferreira, admirado por Jouvet. Trata-se, principalmente de um estímulo ao entendimento de uma cultura e prática teatral em sintonia com o próprio processo cultural onde se inscreve a produção em arte.

\section{Referências bibliográficas}

ANDRADE, Mário. Cartas a um jovem escritor: de Mário de Andrade a Fernando Sabino. Rio de Janeiro. Record, 1981. 
ANGELIDES, Sophia. A. P. Tchékhov: cartas para uma poética. São Paulo. EDUSP, 1995.

GENET, Jean. Lettres à Roger Blin. Paris. Gallimard, 1966.

JOUVET, Louis. Prestiges e perspectives du théâtre français: quatre ans de tournées em Amérique Latine 1941-1945. Paris. Gallimard, 1945.

PRADO, Décio de Almeida. Seres, coisas, lugares: do teatro ao futebol. São Paulo. Companhia das Letras, 1997.

TAKEDA, Cristiane Layher. O cotidiano de uma lenda: cartas do Teatro de Arte de Moscou. São Paulo. Editora Perspectiva / FAPESP, 2003. 